\title{
Country Risk Management in a Developing Country
}

\author{
Adel Al Khattab1, Mahmaod Al-Rawad1, Sliman Al Soboa1, Khamis Al-Khattab² \\ ${ }^{1}$ Department of Accounting, College of Business School, Al-Hussain Bin Talal University, Ma'an, Jordan \\ ${ }^{2} \mathrm{PhD}$ Student, Ain Shams University, Cairo, Egypt \\ Email: adel.alkhattab@yahoo.co.uk, m rawad@yahoo.com, sliman alsoboa@yahoo.com, \\ alkhattab17@yahoo.com
}

Received 5 January 2015; accepted 20 January 2015; published 26 January 2015

Copyright (C) 2015 by authors and Scientific Research Publishing Inc.

This work is licensed under the Creative Commons Attribution International License (CC BY).

http://creativecommons.org/licenses/by/4.0/

(c) $\underset{\mathrm{EY}}{\mathrm{P}}$ Open Access

\section{Abstract}

The recent events in Syria, Iran, Iraq, Tunisia, Egypt, Libya and Pakistan have highlighted the importance of political events to business. Government actions, furthermore, are increasingly pervading all spheres of business activity. Since political events and government actions may affect enterprise performance, there is a need to take them into account in planning and executing strategy. As a response to the increasing impact of political events on business, a new function concerned with the assessment of country risk is gradually emerging in enterprises. Yet, this function is not without its obstacles. This study reports on the obstacles that plague the country risk process in multinational enterprises. In order to achieve this aim, interviews have been conducted with related persons in Jordanian enterprises, who are involved in risk management. It was found that the majority of Jordanian interviewees are unsatisfied with their existing approach for assessing country risk. This research has also offered suggestions for improving practice and offered directions for further research.

\section{Keywords}

Risk Management, International Business and Perceptions

\section{Introduction}

Managers who are involved in international business are at the heart of effective strategy execution. Limited research, nevertheless, exists to understand the process and its obstacles that make managers effective, most notably as they face new challenges brought forth by the changing global economy. The global economic crisis has highlighted the importance of managers in dealing with such obstacles. Furthermore, the changes in the global 
economy may create a need to rethink managerial approaches to deal with risks associated with business and the way they are managed. This is so important in developing country like Jordan.

Jordan is a lower middle income country with a population of 5.9 million and a per-capita GNI of US\$ 3310 as in 2008 [1]. Jordan's economy is dominated by services, which account for over 70 percent of GDP and more than 75 percent of jobs. Notwithstanding the difficult regional political environment and the lack of resources, Jordan has achieved above-average development outcomes within its income group. Underpinned by its strong trade links with the region, Jordan's economy has shown strong performance since 2000 with annual real GDP growth averaging 7.5 percent and per capita GDP more than doubling. Growth has been broad based, led by manufacturing, construction, real estate and services sectors. Inflation remained low (except for the surge in 2008 driven by international oil and food prices) and although the external deficit widened, sizable FDI inflows enabled a steady and sizable increase in international reserves. This can be credited to sound development policies, recent substantial capital inflows and to one of the world's highest levels of unilateral transfers (workers' remittances and public grants, amounting to about 20 - 25 percent of GDP). However, Jordan is vulnerable to adverse external events, such as the fluctuation in world oil and food prices and the global recession as well as deterioration in external flows [2].

The global economic slowdown, starting in the second half of 2008, has created several medium-term challenges for Jordan. The three most important of these are lower global oil prices (which have a positive impact on trade deficit but a negative impact on transfers and capital account), lower private capital flows to developing countries (which were a major source of growth for Jordan in the recent past), and sharply lower global and regional growth outlook (which affect exports and remittances). Reflecting these effects, domestic economic performance has worsened since September 2008. Real GDP growth for the first three quarters of 2009 remained at 2.7 percent, compared to 9.1 percent for the same period in 2008. Sectors that experienced the strongest slowdown are those that benefit from the capital inflows, foreign transfers and foreign demand such as financial services, community and personal services, wholesale and retail trade and manufacturing.

The current account deficit is projected to narrow to less than 8 percent of GDP in 2009 driven by lower economic activity and lower international prices which translate into lower imports. With ongoing recovery in regional wealth and growth, it is also expected that inflows from services, income transfers and capital will improve over time. The risk of external financing difficulties is mitigated by largely prudent policies supporting a measured external adjustment and adequate liquidity. Reserves in foreign currencies of the Central Bank of Jordan (CBJ) increased to a record high US\$ 11.5 billion in December 2009 (equivalent to 8.7 months of imports), up from US\$ 8.6 billion at the end of 2008. The increase in the reserves of CBJ reflects the improvement in external balances and the conversion from foreign currency denominated deposits to Jordanian Dinar denominated deposits, reflecting the interest rate differentials.

Over the last 10 years, as suggested by [3], Jordan has been very active in reforming its economy. It ranks as one of the best reformers compared to other middle income-countries. Despite the progress made, Jordan still confronts several challenges, including those that will arise from the recent global economic slowdown. Challenges include vulnerability to fluctuations in the international oil market, due to the country's high energy import dependency; high unemployment and dependency on remittances from Gulf economies; and increasing pressure on natural resources, especially water. The greatest challenge (and also the largest opportunity) remains the necessity to create adequate conditions for increased private investment and improved competitiveness. This will help to deliver the high and sustainable growth needed to create employment and to reduce poverty. Staying the course with the implementation of the fiscal consolidation program may prove more challenging in the future but is key to preserving good economic performance.

In light of the above economic situation and developments in the literature, this study was undertaken to find out the obstacles that enterprises face in assessing country risk. It was felt that this information would shed some light on why managers tend not to use sophisticated tools even though these are available in the literature. The study also aims at identifying resolution for the obstacles to improve current practice and analyze and generate propositions about country risk in order to advance theory building in this area.

\section{Literature Review}

Risk assessment is a central component of risk management. For multinational enterprises (MNE), where such assessment involves international markets, the assessment, according to [4] and [5], is usually political risk as- 
sessment or country risk assessment (CRA). Country risk, according to [6], refers to the risk of investing in a country, dependent on changes in the business environment that may adversely affect operating profits or the value of assets in a specific country. This term is also referred to as political risk. Country risk, however, is a more general term, which generally only refers to risks affecting all (MNE) operating within a particular country.

A number of sophisticated tools for assessing country risk have surfaced in the literature. There are two broad approaches to risk assessment: heuristic and scientific. [7] explained that a heuristic approach is qualitative and subjective, relying on personnel' collective judgment, while a scientific approach, as reported by [7] includes quantitative modeling and requires formal training in mathematics used. To understand how a risk assessment tool can assist in the process of identifying and quantifying risk, there is a need to understand what a risk analysis is. Risk analysis is the process of identifying the potential for possible harm to occur to a particular set of assets or processes and determining the impact. There are, nevertheless, varying degrees of risk analysis, with each providing differing views of an enterprise's risk profile.

The two primary types of risk analysis processes are qualitative and quantitative. Qualitative is a simplified process of identifying the major threats to which an enterprise is exposed. Basically, one must qualify which risks are worth protecting against. This process is more intuitive and generally can be accomplished in an abbreviated fashion by analyzing the prospected risk; the likely is it to occur and the impact of such occurrence. Quantitative, on the other hand, requires a direct correlation to the value of the assets that require protection. Enterprises are increasingly eager to know what the cost/benefit is to protecting an asset or process. In order to find this information, an advanced risk analysis technique, known as a quantitative approach, is used to provide statistical insight to risk prediction and impact. This method requires that one establish a monetary value for the assets and processes, estimate the probability of a threat occurring.

The review of the country risk literature indicates that, when an international enterprise's management acknowledges the value of risk assessment and deliberately assess country risk, the approaches to risk assessment can be divided into two broad categories: qualitative and quantitative [8]. The first category of tools, according to [9], is qualitative. These tools can be divided into five main tools: judgment and intuition of manager; scenario development; expert opinion; standardized checklist and Delphi technique. The second category of risk assessment tools is quantitative tools. Quantitative tools applied to risk assessment are any analytical procedures that are based on data that can theoretically lend themselves to statistical or mathematical operations [10]. According to [11], such tools were developed in order to reduce the bias of the "subjectivity" of qualitative tools. In view of this, [12] argued that, while the identification of country risk may be a straightforward process, "its measurement and management frequently tend to be more subjective than objective". Similarly, [13] stated that the measurement of country risk depends to a great extent on subjective human judgment which is in some instances a handicap for country risk. [7] suggested that risk is subjective and so-called objective risk is merely a convenient way of expressing the fact that some people share a particular, normative view of risk which implies or seeks to suggest that risk can be distinguished from human bias.

It seems that few empirical country risk studies have included particular qualitative tools (e.g. [11] [14]). Other studies (e.g. [15] [16]) suggested one main technique as an example of quantitative tools: regression analysis. Regression analysis, as defined by [17], is a statistical method used to determine the relationship between the dependent variable and one (simple regression analysis) or more independent variables (multiple regression analysis). A common approach to predict a probability for the occurrence of a certain event is through the use of a number of measurable variables that work as leading indicators. For instance, a high inflation and a low economic growth (independent variables) might indicate an increased probability of political violence (dependent variable). Thus, regression analysis relies on historical relations between the dependent and independent variable.

A review of the empirical studies of country risk indicates that, although qualitative tools are subjective and vulnerable to the bias and errors of the analyst, multinational enterprises tend to use such tools more often than their quantitative counterparts. Such a tendency was reported in the context of Canadian enterprises [16], UK enterprises [18], Dutch enterprises [11], Turkish enterprises [19] and Swedish enterprises [8]. However, there would seem to be little process made to explain this tendency by the aforementioned studies. One available related study is that of [15] who empirically found that large-sized and high-internationalized enterprises were more likely to utilize quantitative tools while no relations to utilization of qualitative tools and enterprise-specific characteristics were found. Therefore, an explanatory process is required in order to shed some light on why multinational enterprises tend not to use quantitative tools even though these are available in the literature. 
Such an explanation can be achieved by both personal interaction with interviewees and exploring potential correlations between enterprise-specific characteristics and the use of quantitative tools.

However, empirical research has shown that few enterprises use these sophisticated tools regularly. The political assessment function appears to be quite varied, ranging from informal assessment by top management to a formal. When assessing the external environment, managers tend to rely heavily on interpersonal contact for their information sources. The integration of the Assessment of country risk into decision-making tends to be informal and unsystematic. Finally, the literature has uncovered a number of strategies that multinational enterprises have used to reduce country risk.

\section{Methodology}

In this study a survey approach has been used to obtain primary data. Such approach is easy to undertake and allow a significant degree of control over the research process. Interviews were employed in this study. It was expected that many enterprises would respond to the interviews, because this research would provide one of the first studies of the obstacles in the field of country risk.

\subsection{Using Semi-Structured Interviews}

Interviews may be highly formalized and structured, using standardized questions for each respondent. Alternatively, they may be informal and unstructured. One typology that is commonly used relates to the level of formality and structure of interviews, whereby the following categories are utilized: 1) structured interview; 2) semi-structured interview; or 3) unstructured interviews.

Structured interviews use questionnaires based on a predetermined and standardized or identical set of questions. The researcher reads out each question and then record the response on a standardized schedule, usually with pre-coded answers. By comparison, semi-structured and unstructured interviews are non-standardized. [20] has suggested that in-depth or semi-standardized interviews can be used to identify variables. The data gathered from such exploratory interviews can then be used in the design of questionnaire. [21] made a point that interviews, presumably semi-structured or in-depth ones, may be used as a means to validate findings from the use of questionnaires. In this study, semi-structured interviews were used.

\subsection{The Interviewees}

A total of fifteen personal interviews were undertaken with managers and associate directors. This process lasted for two months. Using a semi-structured interview approach, a list of questions to be covered varied from interview to interview. Some questions were omitted in particular interviews, in order to account for the specific enterprise background of interviewees. The order of the questions was also varied depending on the flow of the conversation. Additional questions were asked when it was felt that additional research questions could be explored. The outcomes of the interviews were recorded by note taking. Each interview was required more than one hour.

\subsection{Reliability of Interview Outcomes}

The requirement of consistency in semi-structured interviews has lead to concerns about their reliability [22]. Specifically, it has been suggested that alternative interviewers would not report the same information [22] and [23]. Thus, an interviewer's comments or behavior can create bias in the way that interviewees respond to questions. Interviewers may attempt to impose their own beliefs and frame of reference through particular questions. It is also possible that interviewers will demonstrate bias in the way they interpret responses [23].

In order to reduce the doubts about validity and reliability, and to avoid the sources of bias, the following measures were taken in our interviews: a) all interviewees were selected from top management in order to access similar levels of professional competence; b) identical opening comments about the nature of the research questions preceded all interviews; c) a learning approach to questioning was used so as to make interviewees feel confident and elicit as much information as possible.

\section{Results}

The outcomes of the risk manager interviews were based on an analysis of the interviewer's notes. These find- 
ings have been categorized into two categories: a) the obstacles in assessing country risk and b) the visions for country risk management.

\subsection{Obstacles in Assessing Country Risk}

An overriding sentiment expressed by 62 percent of interviewees is the require of satisfaction with their existing approach to assessing country risk. This finding is in accord with that reached by [3] where most enterprises required a satisfactory means of assessing exposure to country risk. Similarly, in the context of UK, [12] found that even those enterprises which have embraced enterprise/business/enterprise risk management have had difficulties in incorporating country risk into their operations. The requirement of satisfaction with the existing approach for assessing country risk by Jordanian enterprises can be attributed to different obstacles.

These obstacles are discussed throughout this research when qualitatively explaining the managerial practices and can be summarized as follows: a) the process of country risk is time consuming, which may also lead to postpones in preparing the outcome, so the outcomes can also be out-dated; b) the data required to use quantitative tools may not be readily available and, if available, data tend to be in the wrong format and biased because such data are collected for purposes other than risk assessment; c) the use of quantitative tools requires a statistical background and use of a computer. In addition, interpreting outcomes also needs particular skills; d) downward communication from management at the decision-making level to risk assessors, is limited, which also means that the risk assessment process seems to have received no apparent support from top management.

However, interviews with those managers who were positive towards their assessment processes, revealed two main themes: satisfaction with existing arrangements and disbelief about the assessment's outcomes. A financial enterprise, for instance, assesses country risks when "necessary" describing his approach as "pragmatic". Even if the need is conceded, the respondent believes that formal assessment cannot yield better outcomes than he does. The satisfaction with existing arrangements is linked to another reason; skepticism. A bank, for instance, is negative toward the need for formal country risk. To this end, both satisfaction with existing arrangement and skepticism about the findings provide a rationale for why some enterprises need not do more in assessing country risk.

Not all investments warrant a country risk: some investments involve no country risk exposure. For instance, a financial enterprise has a policy that requires advance payment before undertaking any international operations. However, interviewees considered country risk important to their enterprise's investments and believe that there is a require of satisfaction with their existing system of assessing country risk; while interviewees felt that country risk is an important factor affecting their foreign investments they did not feel they had realized the full promise of the assessment process. Upon deeper probing, the flowing reasons for the interviewees disaffection with their assessment system emerged: postponed report, imprudent assessment, data confront, misrepresentation of information, inappropriateness information, requirement of skills and require of top management support.

In addition to highlighting these obstacles with concrete examples, some resolution undertaken by enterprises are offered. It should be made clear that these obstacles are not mutually exclusive: an enterprise may suffer from more than one obstacle. Moreover, the likelihood of an obstacle seems to suffer from more than one obstacle. In addition, the likelihood of an obstacle seems to depend on whether the political assessment function is delegated to a personnel department or is conducted informally by top management. The use of quantitative tools, however, requires "statistical background" and the use of computers. In addition, interpreting outcomes needs particular skills. Subsequently, two obstacles face multinational enterprises in assessing country risk: require and/or inappropriateness of information and require of skills required for risk assessment.

Thus, enterprises utilize quantitative tools less frequently than qualitative tools. It is intuitional, therefore, to propose that enterprises which utilize quantitative tools may differ in some characteristics to those enterprises that do not use such tools. Indeed, enterprises that used quantitative tools are larger in size (median US\$ 30.12 million versus US\$ 9.91 million), have more years in international business (median 17 versus 11), generate higher revenue from international business activities (median 17.1\% versus $8.2 \%$ ) and have facilities in more countries (median 8.6 versus 5.5). An early study by [15] found that high-internationalized enterprises (enterprises with $\geq 20.0$ percent of their sales generated by international operations) were more likely to utilize quantitative tools than low-internationalized enterprises since the former enterprises have more resources to use such tools. 


\subsubsection{Postponed Reports}

According to [24], the preparation of an in-depth country risk study involving the assembly of experts, collection of data, analysis, and prediction of the impact of future events on the enterprise is a time-consuming process. However, management may be confronted with a sudden investment opportunity that requires an immediate commitment of resources. If management waits for a study to be completed before investing the opportunity may disappear, while if it decides to commit its resources it must do so without the information about the future that an assessing study provides. In addition, the time consuming nature of an assessing process implies that the report may be out-dated by the time it is completed.

Some enterprises have undertaken resolution in their assessment process to cope with the postpone obstacle. Instead of conducting an in-house study, which is time-consuming; these enterprises buy ready-made reports about a particular country. However, these studies often cover only the general political conditions in a country but not national origin, industry, enterprise and product-specific sources of country risk. Another possibility is to hire a consultant for that particular country to obtain quick and relevant information.

\subsubsection{Thoughtless Assessment}

An important reason why quick action may not be taken by management is that the assessment process tends to be imprudent rather than practical. A country risk study is usually motivated by the intention to evaluate an investment proposal or to monitor the climate of an existing investment. If the assessment process does not anticipate investment proposals, quick action may not be possible. The common imprudent stance seems to occur because assessment resources are limited and therefore used cautiously. However, risk manager favored adopting a more practical stance that would entail instable countries that were considered to have a high country risk. The remaining countries would then be considered as possible investment locations. In his view, this procedure would avoid the obstacle of soliciting investment proposals in areas of high country risk.

\subsubsection{Data Confrontment}

The effective use of sophisticated country risk tools, such as Delphi, time series analysis, regression analysis and surveys may be impeded, as reported by [25], by data confront. Data can be defined as factual information, especially information organized for analysis or used to reason or make decisions. Proper data that are required as an input into the analytical models often are not readily available. Firstly, collection of political data is difficult and time-consuming, in particular in the developing countries. One country risk expert who has conducted extensive primary research work in the developing countries, commented: as a foreigner it is very difficult to ask the local people politically sensitive information because this elicits patriotic sentiments and defensiveness. If the actual interviewing is delegated to local interviewers a control obstacle arises. Moreover, in many countries the secondary sources of information, such as newspapers, may be censored and leave out material that may be important to a country risk manager. Information on strikes, police arrests, and guerilla activity may not be disclosed. Documentation and permanent records of political information tend not to exist. Data that are available tend to be in the wrong format and biased because they are collected for another purpose. For instance, a common practice among multinational enterprises is to use the government enterprises as a source of information about country risk in foreign countries. However, since the interest and focus of such governmental enterprise is usually different from that of multinational enterprises, information collected by governmental enterprises may not be very useful. In order to tackle this obstacle, a financial enterprise hires an independent consultant. By cross checking information from different sources, biases in date can be detected. Risk managers tend to be unconfident about the reliability of political data. Remarked one risk manager: why should we use sophisticated tools on data with which we have no confidence. Sophisticated analytical tools on political data give the appearance of accuracy and a false sense of scientific security commented another risk manager.

\subsubsection{Misrepresentation of Information}

Information, as suggested by [26], is knowledge of specific events or situations that has been gathered or received by communication; intelligence or news. Interviewees, however, have repeatedly identified during the interviews the misrepresentation of information as an important obstacle in the assessment process. The misrepresentation of information appears to be caused by internal politics and a communication obstacle arising from differences in personal orientation and from the nature of political data. Misrepresentation, as a outcome of internal the fear of loss of power removal of discretionary authority, and relegation to an inferior departmental or 
divisional status prompts enterprise members to screenland select information in the assessing process. Information that proves damaging to one's status may be withheld or given an interpretation to suit one's position. For instance, in a bank (C), subsidiary managers are responsible for submitting to top management a periodic assessment of the political conditions in that country for the ongoing investment. however, top management does not take the report at face value because it feels that it will be too optimistic "No subsidiary manager would like to see his capital allocation cut" in addition to the report of the subsidiary manager, management hires a consultant to visit the country every six months and to submit a separate report as an independent assessment. Top management risk manager also travel to the host country to see for themselves what is brewing.

Misrepresentation of information as an outcome of communication difficulties: differences in personal orientation of enterprise members can, as suggested by [27], affect the comfort level with different types of information. Some personnel have a high tolerated for ambiguity while others prefer a more structured setting. The information generated in a country risk analysis is usually unclear and nondeterministic. For instance revolutions may occur with or without having an impact on an investment legal restrictions may be enacted but not enforced a particular set of preconditions may facilitate a military takeover in one country but not in another. Furthermore political data being ambiguous is easily interpreted in different ways. Misrepresentation may be the outcome of faulty communication arising from obstacles of perception and transmission of information. For instance, in a financial enterprise, risk manager have a quantitative background, the enterprise has a formal political assessment unit which is staffed by political scientists when the political scientists attempt to relay the country risk assessment to top management misunderstanding erupt top interviewees feel uncomfortable and have difficulty coping with the ambiguity of the information contained in a predominantly qualitative report a frequent outcomes is for the frustrated top risk manager to demand "give me a number from 0 to 100 that indicates the country risk for our investment in country X”.

To overcome this obstacle, interviewees may consider adapting the report to fit the culture of the users although this moves likely to outcome in a loss of formation. Alternatively, the interjection of a mediator between top management and the Personnel department may reduce communication obstacles arising from differences in orientation. In a financial enterprise, the obstacle was solved by placing a quantitatively-oriented manager through a political science training program. Upon completion of the training program this manager served as a liaison between top management and the country risk unit.

\subsubsection{Inappropriateness of Information}

A common obstacle frequently mentioned by the interviewees is the inappropriateness of most of the information to which they are exposed. For instance, in a financial enterprise the interviewee mentioned that "too much information of the wrong kind, not enough of the right kind". Analysts in the personnel department may not know what kind of information management would like to have when designing a strategy. Consequently, if risk assessors do not know what type of information to look out for, they are likely to compile a report full of irrelevant information. For instance, in a financial enterprise, management requested a staff analyst to make a political conditions study of a one country. Deeper probing during the interview, however, showed that the analyst was not told the size or type of investment the management was contemplating. Without product and enterprise specific information, it was difficult for the risk assessor to determine what type of information was relevant to the investment. But even knowing more particulars about the investment would not have totally solved the inappropriateness of information obstacle in assessing the political environment. This is because of the non-deterministic relationship between political instability and country risk. For instance, if revolutions may occur but have no impact on a foreign investment, information about the occurrence of a revolution is not relevant.

Interviewees that receive the report dismiss most of the information as irrelevant because it tends not to be actionable. The users of the assessment may not know how the information that is provided can be utilized in designing a strategy. One possible resolution for the inappropriateness of information obstacle is management to start a process by cautiously defining the enterprise's strategy so that the relevant information can be determined in the assessing process. This eliminates unfocused, assessing that would outcome in a waste of resources and the incomprehension of the risk assessor. However, the enterprise's strategy should be flexible enough to permit adaptation based on the feedback of information from assessing. It is through this cycle that defining strategy helps assessing. Another common method to reduce the inappropriateness of information obstacle is to obtain information from other enterprises from the same industry and national origin that are already operating in the country of interest. This method tends not only to be inexpensive, but also focuses the assessing process by hig- 
hlighting national origin, product and industry-specific sources of country risk.

\subsubsection{Requirement of Skills}

Skills can be defined, as suggested by [28], as proficiency, facility, or dexterity that is acquired or developed through training or experience. Managers tend not to believe in assessment that is generated by complicated assessing tools that they do not realize. As one risk manager put it: "I just don't think that events such as kidnappings are predictable so when I get such an assessment I disbelief the report and the assessing tools themselves.” In addition, without an in-depth knowledge of the assessment methodology, top management is not likely to direct the staff's processes to other productive areas of application.

\subsubsection{Requirement of Top Management Support}

When evaluating an investment proposal, top interviewees, according to [29], consider several types of risks: technological, political, economic, foreign exchange, etc. An investment enterprise has a particular pattern of risks and top management tends to evaluate these risks jointly. If an enterprise is exposed to considerable country risk, but has low technological and economic risk, it may still be approved by the management. However, if the political assessment unit has damned the enterprise because of its high country risk, the staff is likely to be dejected when the investment go ahead is given. If reasons for the enterprise's acceptance are not made clear to the staff in the political assessment unit, a bad morale obstacle is likely to develop. For instance: the management of the financial enterprise, usually considers country risks and the technical risks of development before making an investment.

\subsection{Scenario for Country Risk Management}

Although interviewees are acquainted with country risk to be an important determinant of enterprise performance, they seem to be disappointed with their assessing process. Undoubtedly the obstacles mentioned above contribute to their disappointment. If the country risk process is to be made more effective, the obstacles need to be determined. In general, the resolution to the commonly observed obstacles seems to fall into two categories: firstly, those involving changes in the political assessment technology and, secondly, those involving changes in the internal enterprise of the enterprise to make the assessment process more effective. Although both types of resolution can be used together, managers in enterprises with an inflexible enterprise may find that changes in technology may be easier to implement than adapting internally. It should be pointed out, however, that considering the nature of the obstacles that outbreak the assessment function, not much appears to be gained by developing more complicated assessing tools which may only make existing obstacles of inadequate data, communication, and postpone more sensitive.

In recognition of the obstacles in assessing country risk, and of the fact that even if country risk is predicted something must be done about it, interviewees are devoting more process into trying to work out the differences with the governments. According to one risk manager, "assessing that there will be a storm in the future is not as important as being able to ride through the storm". The chairman of an industrial enterprise expressed his idea: "I believe that our enterprise should try to work with the government in resolving any differences that may arise". The interviews evoked a number of creative conflict management strategies that have just begun to surface in the literature on strategies to cope with country risk.

The enterprise that was to set up in another Middle Eastern country involved design work, procurement of materials, and local assembly. Since the enterprise's normal need of materials involved purchases from parties affiliated with non-desired countries, which would not be acceptable to the host country, it decided to break up the enterprise into the three parts: design work, procurement, and assembly. The procurement of materials was entrusted to the host country while the enterprise continued to perform the design work and assembly which did not involve a conflict between the two countries.

An industrial enterprise, has a subsidiary in an another Asian country that was facing increasing government pressure in the form of higher taxes, local content requirements, minority employment regulations, and import restrictions on unprocessed materials. Top management knew that the government badly needed foreign exchange to boost its balance of payments position. With this information in mind, top management was able to negotiate an agreement with the government that the enterprise would guarantee the country a minimum volume of exports a year from the subsidiary in return for relaxation of government restrictions on imports, taxes, local 
content, and employment. Government actions, however, were reducing the international competitiveness of the products made locally; management was able to hit a deal with the government to reduce restrictions on the subsidiary in return for exports.

\section{Conclusions and Implications}

There are numerous studies discussing sophisticated country risk tools. Most of these tools, however, appear not to be used widely in enterprises because of a number of obstacles plaguing their country risk process. Resolution for some of these obstacles which managers can use to improve the assessment function seems to involve changes in the assessment technology and changes in internal enterprise. Creative conflict-management also appears to be a promising area to reduce country risk.

An overriding sentiment, however, expressed by the majority of Jordanian interviewees is the requirement of satisfaction with their existing approach for assessing country risk. This dissatisfaction has been attributed to many obstacles that managers face while being involved in the assessment. Further research is needed in order to provide a clear understanding of the obstacles that managers face in assessing country risk. There is also a need to identify resolution for the obstacles in order to improve current practices.

More research work on creative conflict engagement between the government and the multinational enterprise seems to be a promising vision. Such research should focus not only on the content of the strategy, but also on the process of strategy formation involving negotiations with the government. On the whole, much remains to be learned about country risk management within multinational enterprises. It is hoped, however, that this research will motivate international business academicians and practitioners alike in further examining what is considered a fruitful area of research.

\section{References}

[1] World Bank (2010) Jordan, Country Brief.

[2] World Bank (2011) Jordan, Country Brief.

[3] Dawaemah, S. (2011) Economic Indicators on Jordan. Jordan Bulletin, 2012.

[4] Stapenhurst, F. (1992) The Rise and Fall of Political Risk Assessment. Management Decision, 30, 54-57.

[5] Al Khattab, A. (2006) Political Risk Assessment in Jordanian International Firms. Ph.D. Thesis, University of Huddersfield, Huddersfield.

[6] Wilkin, S. (2001) Making Political Risk Fit. Risk Management, 48, 80.

[7] Waring, A. and Glendon, I (2001) Managing Risk. Cengage Learning Business Press, London.

[8] Kettis, M. (2004) The Challenge of Political Risk: Exploring the Political Risk Management of Swedish Multinational Corporations. Ph.D. Thesis, Stockholm University, Sweden.

[9] Thurik, R. (1993) Exports and Small Business in the Netherlands: Presence Potential and Performance. International Small Business Journal, 11, 49-58. http://dx.doi.org/10.1177/026624269301100303

[10] Ting, W. (1988) Multinational Risk Assessment and Management: Strategies for Investment and Marketing Decisions. Quorum Books, New York.

[11] Knowles, W. (2005) Jordan since 1989: A Study in Political Economy. I.B. Tauris, London.

[12] Hood, J. and Nawaz, M.S. (2004) Political Risk Exposure and Management in Multi-National Companies: Is There a Role for the Corporate Risk Manager? Risk Management: An International Journal, 6, 7-18. http://dx.doi.org/10.1057/palgrave.rm.8240169

[13] Brink, C. (2004) Measuring Political Risk: Risks to Foreign Investment. Ashgate Publishing Limited, Farnham.

[14] Atkinson, C. (2002) Forget Sovereign Bankruptcy Plans. Financial Times, 17 May 2002.

[15] Bouchet, M. and Hay, J. (1988) The Rise of the Market-Based "Menu” Approach and Its Limitations. World Bank, CFS Informal Financial Note No. 5, ISBN 0-470-84500-7.

[16] Moran, T.H. (2001) Preferred Creditor Status: Overview. In: Moran, T.H., Ed., International Political Risk Management: Exploring New Frontiers, The World Bank Group, Washington DC.

[17] SPSS (2012) IBM SPSS Statistics for Windows, Version 20.0. IBM Corp., Armonk.

[18] Ikawa, M. (2001) Introduction. In: Moran, T.H., Ed., International Political Risk Management: Exploring New Frontiers, The World Bank Group, Washington DC. 
[19] Demirbag, M. and Gunes, R. (2000) Political Risk Assessment: A Case Study of Turkish Companies Operating in Central Asian and Russian Markets. Attie Monografie, 31, 105-120

[20] Hair, J., Babin, B., Money, A. and Samouel, P. (2011) Essentials of Business Research Methods. International Edition, John Wiley and Sons, Hoboken.

[21] Sekaran, U. (2010) Research Methods for Business: A Skill-Building Approach. 4th Edition, John Wiley \& Sons, UK.

[22] Robson, C. (2002) Real World Research: A Resource for Social Scientists and Practitioners. 2nd Edition, Brequirewell Publishers, Oxford.

[23] Saunders, M., Lewise, P. and Adrian, T. (2013) Research Methods for Business Students. 3rd Edition, Prentice Hall, London.

[24] Varetto, F. (1998) Genetic Algorithms Applications in the Analysis of Insolvency Risk. Journal of Banking and Finance, 22, 1421-1439. http://dx.doi.org/10.1016/S0378-4266(98)00059-4

[25] Barney, J.B. (1991) Firm Resources and Sustained Competitive Advantage. Journal of Management, 17, 99-120. http://dx.doi.org/10.1177/014920639101700108

[26] Boyer, K. and Lewis, M. (2002) Competitive Priorities: Investigating the Need for Trade-Offs in Operations Strategy. Production and Operations Management, 11, 9-20.

[27] Cepeda, G. and Vera, D. (2007) Dynamic Capabilities and Operational Capabilities: A Knowledge Management Perspective. Journal of Business Research, 60, 426-437. http://dx.doi.org/10.1016/j.jbusres.2007.01.013

[28] Frynas, J.G. and Mellahi, K. (2003) Political Risks as Firm-Specific (Dis)Advantages: Evidence on Transnational Firms in Nigeria. Thunderbird International Business Review, 45, 541-565. http://dx.doi.org/10.1002/tie.10090

[29] Cardy, R.L. and Selvarajan, T.T. (2006) Competencies: Alternative Frameworks for Competitive Advantage. Business Horizons, 49, 235-245. http://dx.doi.org/10.1016/j.bushor.2005.09.004 
Scientific Research Publishing (SCIRP) is one of the largest Open Access journal publishers. It is currently publishing more than 200 open access, online, peer-reviewed journals covering a wide range of academic disciplines. SCIRP serves the worldwide academic communities and contributes to the progress and application of science with its publication.

Other selected journals from SCIRP are listed as below. Submit your manuscript to us via either submit@scirp.org or Online Submission Portal.
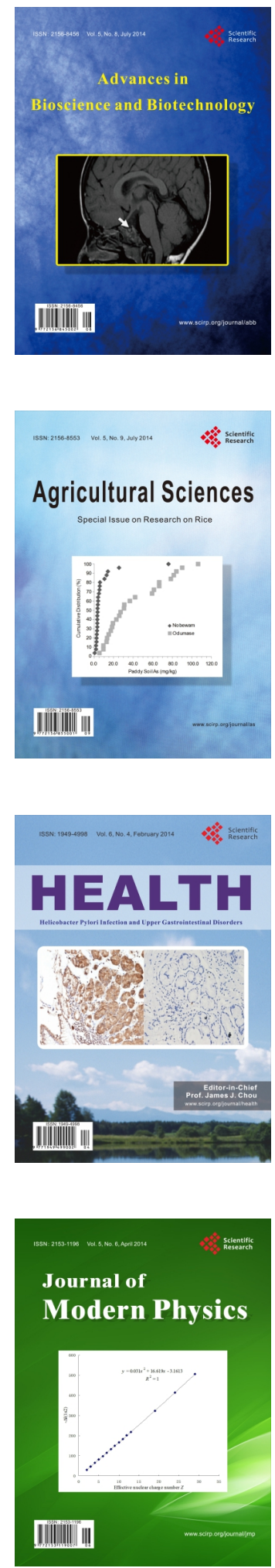
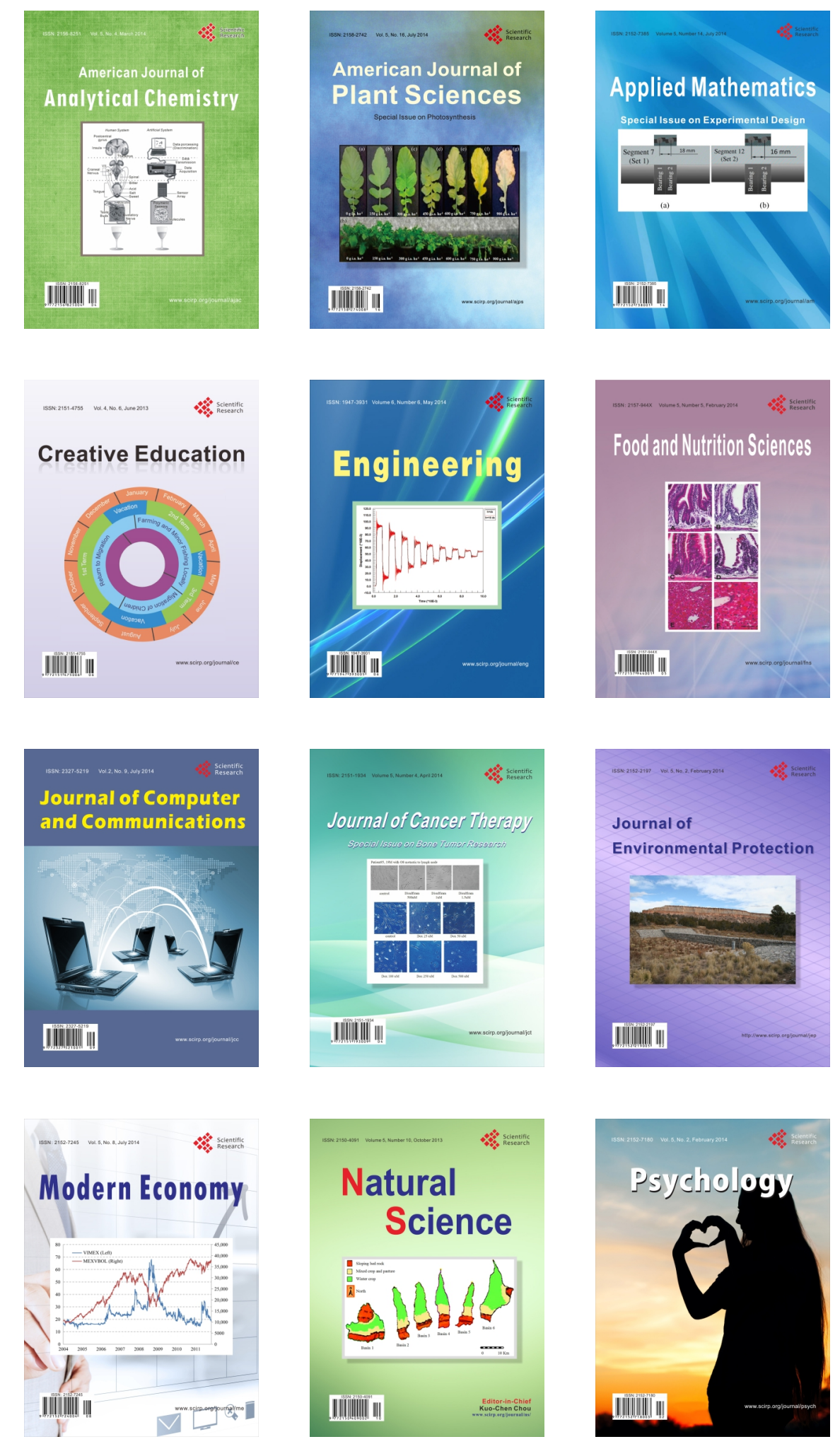